\title{
KESEDERHANAAN WABICHA DALAM UPACARA MINUM TEH JEPANG
}

Fajria Noviana

Program Studi Bahasa dan Sastra Jepang FIB Universitas Diponegoro

Email: fajria_noviana@yahoo.com

\section{ABSTRACT}

The Japanese tea ceremony is called chanoyu in Japanese. It is a multifaceted traditional activity strongly influenced by Zen Buddhism, in which powdered green tea, or matcha, is ceremonially prepared and served to the guests. Wabicha is a style of Japanese tea ceremony particularly associated with Sen no Rikyū that emphasizes simplicity. He refined the art of Japanese tea ceremony equipment and tea house design, with a preference for very simple and very small tea rooms, and natural materials with simpler decoration.

Keywords: chanoyu, chashitsu, wabi, sabi, wabicha

\section{PENDAHULUAN}

Chanoyu, atau dalam bahasa Indonesia disebut upacara atau ritual minum teh, merupakan salah satu ragam budaya tradisional yang masih tetap lestari di Jepang. Meskipun berasal dari daratan Cina, tetapi dunia lebih mengenal chanoyu sebagai budaya Jepang. Istilah chanoyu apabila ditulis dengan aksara Jepang akan menjadi 茶の湯 yang terdiri dari tiga karakter. Arti tiap-tiap karakter yaitu 茶 (cha) adalah teh, の (no) adalah partikel yang menunjukkan keterangan atas sesuatu, dan 湯 ( $y u$ ) adalah air panas. Jadi secara harfiah chanoyu berarti air panas yang dituangkan ke dalam teh. Hal ini dapat dipahami sebagai cara menghidangkan teh dalam upacara tersebut oleh sang tuan rumah kepada tamu-tamunya.

Selain arti seperti disebutkan di atas, chanoyu juga dapat diartikan sebagai suatu kegiatan dalam menyajikan dan menikmati minuman teh yang berstruktur cukup rumit antara pembawa upacara dan tamu yang dihormati (Sadler, 1962:3). Ritual ini dalam pelaksanaannya tidak dapat dilepaskan dari unsur seni, misalnya seni arsitektur taman dan ruang yang digunakan sebagai tempat dilangsungkannya chanoyu. Selain itu, dalam ritual ini juga terkandung unsur interaksi sosial, tata krama, dan kepekaan terhadap lingkungan alam. Danandjaja (1997: 28) mengatakan:

"Upacara minum teh di Jepang
merupakan sebuah $\begin{array}{r}\text { kegiatan } \\ \text { kemasyarakatan yang diciptakan }\end{array}$
untuk menghargai semua kehidupan
dan benda. Upacara ini dilakukan
untuk mengidealisir lingkungan
hidup; untuk menciptakan kehidupan
yang sempurna; keadaan yang tenang
dan keselarasan; dan untuk
menghargai orang lain dan benda-
benda dengan memperhatikan
kebersihan dan ketertiban, yang
membawa kedamaian raga dan
jiwa."

Ritual minum teh yang merupakan salah satu seni tradisional ini memiliki sekitar 36 aliran yang harus dipelajari secara khusus. Tidak cukup hanya dipelajari atau dipraktekkan saja, namun juga harus terus diperdalam dan disempurnakan, yang kadang memakan waktu bertahun-tahun, bahkan mungkin juga seumur hidup.

Wabicha adalah salah satu dari sekian banyak aliran dalam chanoyu. Istilah wabicha apabila ditulis dengan aksara Jepang akan menjadi 侘茶 yang terdiri dari 
dua karakter. 侘 (wab) berasal dari kata 侘 しい (wabishii) yang berarti kesederhanaan, sementara 茶 (cha) sama dengan pada chanoyu. Jadi wabicha dapat diartikan sebagai aliran upacara minum teh dengan sarana (ruang, peralatan, dan lain-lain) yang sederhana.

\section{LANDASAN TEORI}

\subsection{Penelitian Terdahulu}

Tulisan Erika Wahyu
Mimprihati berjudul Penerapan wa, kei, sei,
jaku Dalam Chanoyu menekankan pada
penerapan keempat prinsip dalam chanoyu
tersebut. Hal tersebut berbeda dengan tulisan
ini yang menitikberatkan pembahasan pada
penerapan prinsip kesederhanaan dalam
chanoyu.

\subsection{Sejarah Chanoyu}

Mengingat banyaknya artikel tentang sejarah chanoyu, maka sejarah ritual ini yang dituliskan di subbab ini merupakan hasil rangkuman hanya dari The Book of Tea (Okakura, 1989) dan Historical Chanoyu (Plutschow, 1986).

Teh sebenarnya baru dikenal di Jepang seiring dengan masuknya agama Buddha dari Cina pada periode Nara (7941192). Pada masa itu, teh hanya ditanam di kuil dan dianggap sebagai barang mewah, sehingga hanya bisa dinikmati oleh golongan pendeta atau bangsawan. Sementara chanoyu baru diperkenalkan di Jepang pada periode Kamakura (1192-1333) oleh seorang pendeta Buddha Zen bernama Eisai sekembalinya dari Cina untuk mempelajari agama Buddha. Eisai memperkenalkan ritual minum teh ini karena menurut tradisi Buddha, teh digunakan untuk menambah kesiagaan selama bermeditasi. Setelah itu, seiring dengan makin berkembang dan meluasnya ajaran Buddha Zen, chanoyu juga turut berkembang di Jepang.
Chanoyu pada awalnya hanya diselenggarakan di lingkungan kaum bangsawan, dan biasanya dilakukan sebagai salah satu cara untuk merayakan kejadian penting yang berkaitan dengan kaum bangsawan tersebut. Ritual ini dilaksanakan di dalam chashitsu, atau ruangan kecil khusus untuk melaksanakan chanoyu, yang pada masa itu hanya dimiliki oleh kaisar dan kaum bangsawan. Peralatan, hiasan, dan makanan yang disajikan sangat mewah dan beragam, sehingga pada masa itu chanoyu dianggap sebagai perayaan yang menekankan pada kemewahan.

Sen no Rikyū (1522-1591) adalah salah seorang tokoh chanoyu yang membawa pemikiran tentang kesederhanaan ke dalam ritual tersebut. Rikyū adalah seorang penganut setia Buddha Zen -salah satu ajarannya adalah tentang kesederhanaan- yang berpendapat bahwa chanoyu seharusnya dapat diikuti oleh semua golongan masyarakat. Pemikiran Rikyū ini ternyata mendapat perhatian dan dukungan dari Toyotomi Hideyoshi, seorang bangsawan yang berpengaruh di masa itu. Hideyoshi meminta Rikyū untuk menjadi pembawa upacara pada tiap chanoyu yang ia selenggarakan. Sejak saat itu Rikyū dikenal sebagai tokoh yang berhasil membawa jiwa wabi dalam setiap ritual minum teh yang ia bawakan, yang kemudian disebut dengan wabicha ${ }^{1}$. Dengan mempertahankan pemikiran tersebut, Rikyū berhasil membuat chanoyu, atau wabicha, tetap eksis sampai sekarang.

Seiring dengan perubahan pandangan tentang chanoyu, chashitsu kini juga dibangun di kuil, universitas, sekolah, bahkan tempat kursus yang menyelenggarakan kursus chanoyu. Ruangan ini acapkali dibangun terpisah dari bangunan utama atau dibangun menempel dengan bangunan utama, dengan dikelilingi oleh taman kecil. Hal ini disebabkan oleh telah dimulainya ritual tersebut sejak sebelum memasuki chashitsu, jauh sebelum saat meminum teh itu sendiri.

\footnotetext{
${ }^{1}$ Karena istilah ini dianggap kurang familiar, maka penyebutan upacara minum teh dengan jiwa wabi pun tetap menggunakan istilah chanoyu.
} 


\subsection{Prosesi Chanoyu}

Prosesi chanoyu yang dijelaskan di bawah ini merupakan hasil rangkuman dari The Book of Tea (Okakura, 1989).

Tamu-tamu yang khusus diundang untuk menghadiri ritual ini akan duduk di taman kecil di luar chashitsu menunggu sang tuan rumah datang untuk menyambut mereka. Tamu-tamu ini berjumlah maksimal tiga orang karena keterbatasan ukuran chashitsu, sehingga tidak dimungkinkan dalam satu kali upacara diikuti oleh lebih dari empat orang sekaligus dalam satu ruangan. Setelah sang tuan rumah muncul, para tamu tersebut akan dipersilakan untuk membasuh tangan dan mulut mereka dengan khidmat dalam bejana batu yang sudah disiapkan di luar chashitsu.

Para tamu ini kemudian akan memasuki chashitsu satu per satu melalui pintu yang sangat rendah yang disebut nijiriguchi, kemudian duduk bersimpuh di lantai tatami dengan beralaskan bantal khusus untuk duduk di lantai. Lantai tatami adalah lantai yang dibuat dari susunan beberapa tatami berbentuk persegi panjang, yang disusun sedemikian rupa hingga menutupi seluruh areal lantai. Tatami adalah penutup lantai ruangan yang dibuat dari anyaman jerami halus. Ukuran tatami sendiri merupakan ukuran baku $(0,9 \times 1,8$ meter), sehingga ukuran ruangan dalam rumah tradisional Jepang cukup disebutkan dengan jumlah tatami yang menutupi lantai ruangan tersebut. Ukuran chashitsu sendiri adalah 41/2 tatami $\left(8,93 \mathrm{~m}^{2}\right)$.

Setelah duduk, para tamu akan diberi waktu untuk mengamati hiasan dalam tokonoma (ceruk dalam ruangan sebagai tempat menggantungkan dan meletakkan hiasan). Hiasan itu umumnya berupa kakejiku (hiasan dinding berupa lukisan khas Jepang) atau haiku (puisi Jepang) atau kutipan yang diambil dari kitab suci atau kata-kata yang berhubungan dengan chanoyu itu sendiri, yang ditulis dengan aksara kanji dalam bentuk kaligrafi, dan chabana (rangkaian bunga khusus untuk chanoy). Kemudian sang tuan rumah akan membacakan haiku bagi para tamunya.

Setelah pembacaan haiku, kepada para tamu disajikan satu set hidangan lengkap yang disebut chakaiseki yang terdiri dari nasi putih, semangkuk sup, dan hidangan laut yang umumnya berasa masam dan sayuran, yang harus dimakan sampai habis. Setelah semua prosesi tersebut, barulah para tamu akan dapat menikmati teh dalam chawan (mangkuk teh) dan wagashi (makanan kecil) yang rasanya manis yang disediakan oleh tuan rumah. Teh tersebut diseduh langsung di hadapan para tamu, supaya dapat diminum selagi hangat-agakpanas. Sebelum meminum teh yang disajikan, semua peserta akan menikmati wagashi yang manis lebih dulu.

Setelah para tamu selesai menyantap wagashi, tuan rumah akan membersihkan peralatan minum teh sebelum menyajikan teh. Teh disajikan dengan memasukkan tiga sendok matcha (bubuk teh hijau yang biasa digunakan dalam chanoyu) ke dalam chawan, lalu dituangi air panas kemudian diaduk dengan chasen (pengaduk teh yang terbuat dari bambu). Tamu akan menerima chawan tersebut dengan tangan kanan dan diletakkan di tangan kiri, lalu diputar dua kali searah jarum jam, kemudian meminumnya melalui sisi chawan yang tidak bermotif. Setelah menghabiskan teh, sang tamu membersihkan sisi chawan tempat dimana ia meminum teh dengan jarinya lalu membersihkan jarinya dengan semacam serbet kertas kecil yang sudah tersedia, baru kemudian ia mengembalikan chawan tersebut kepada tuan rumah.

Berikut ini adalah gambar denah bagian dalam chashitsu.

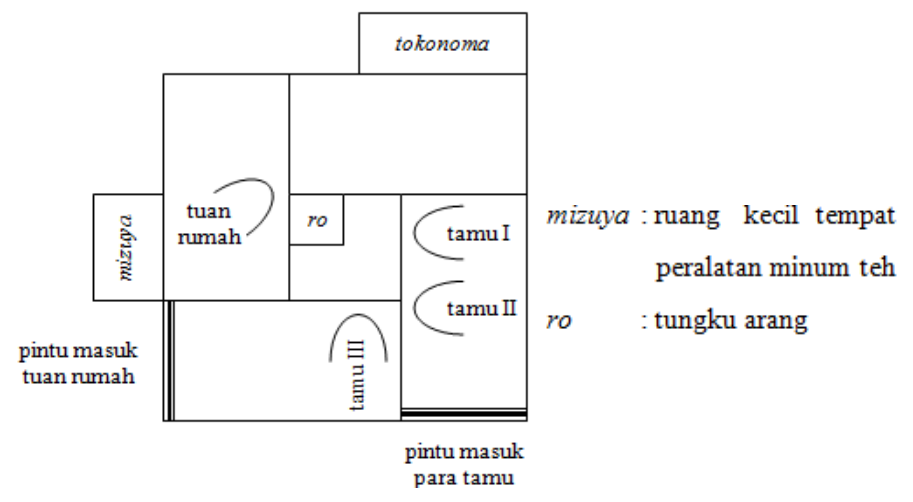

Sebagai catatan, kotak-kotak dalam denah di atas menunjukkan tatami. 


\section{PEMBAHASAN}

\subsection{Makna dari Aktivitas-aktivitas Dalam Prosesi Chanoyu}

Dalam prosesi chanoyu, tiap aktivitas -baik yang dilakukan oleh tuan rumah maupun para tamunya- ternyata memiliki makna tersendiri yang sangat dalam. Berikut ini akan dijelaskan makna dari aktivitas-aktivitas dalam prosesi tersebut.

1. Oleh tuan rumah

a. Membacakan haiku

Karena isinya diilhami dari ajaran Buddha Zen, maka pembacaan haiku ini bertujuan untuk mengajak siapa saja yang mendengarkan untuk menjalankan hidup dengan kesederhanaan sesuai ajaran Buddha Zen, sekaligus sebagai sarana pembersihan rohani

Berikut adalah contoh haiku karya Bashō Matsuo :

\begin{tabular}{cl}
\multicolumn{1}{c}{$\begin{array}{l}\text { 静かさや } \\
\text { iru }\end{array}$} & Shizukasa ya \\
岩に染み入る & Iwa ni shimi-
\end{tabular}

$$
\text { 蟬の声 Semino koe }
$$

Haiku ini bercerita tentang ketenangan dan keheningan. Tak ada suara dan bunyi yang terdengar, kecuali satu atau dua ekor jangkrik yang sesekali terdengar berbunyi lirih yang menghanyutkan dan seakan-akan membuat orang yang mendengarnya menyatu dengan keheningan alam di sekitarnya.

b. Membersihkan peralatan minum teh sebelum menyajikan teh dan setelah teh habis diminum

Karena kemurnian identik dengan kebersihan, maka semua peralatan harus tetap bersih supaya kemurnian ritual dan orang-orang yang hadir di dalamnya tetap terjaga c. Menambahkan air dingin ke dalam mizusashi ( ketel air panas )

Simbolisasi pesan untuk tidak hanya mengambil sumber alam, tetapi juga wajib untuk mengembalikan keadaan seperti semula

d. Mengulurkan chawan dengan tangan kanan dan dengan posisi motif chawan menghadap kepada tamu Menghormati tamu dengan memberikan yang terbaik

2. Oleh para tamu

a. Merunduk saat masuk melalui nijiriguchi

Menunjukkan sikap rendah hati dan hormat, serta untuk menghapuskan perbedaan status sosial

b. Mengamati hiasan dalam chashitsu Menghormati tuan rumah dengan menghargai karya seni yang dimilikinya

c. Menghabiskan hidangan nasi

Rasa syukur atas berlimpahnya makanan yang berasal dari daratan dan lautan

d. Menikmati wagashi

Mempersiapkan lidah untuk rasa teh yang agak pahit dengan wagashi yang rasanya manis

e. Menerima teh dengan tangan kanan Menghormati yang memberi

f. Memutar chawan dua kali searah jarum jam sebelum meminum teh Menghindari meminum teh dari bagian chawan yang bermotif supaya tidak merusak karya seni

g. Membersihkan bagian chawan tempat teh diminum

Kemurnian identik dengan kebersihan, oleh karena itu semua peralatan harus tetap dijaga kebersihannya 
h. Mengamati chawan

Menghormati tuan rumah dengan menghargai karya seni yang dimilikinya

3. Oleh tuan rumah dan para tamu

a. Memberi salam dengan membungkukkan badan

Menunjukkan sikap saling menghormati, dapat menjaga emosi, dan dapat memahami perasaan orang lain

b. Membasuh tangan dan mulut

Simbol pembersihan jasmani dan rohani

c. Membawakan/mengikuti chanoyu dengan tenang dan bergerak dengan halus

Merupakan filosofi meditasi, dimana chanoyu akan membuat orang tenang secara jasmani dan rohani, menghilangkan stres, melupakan sejenak gemerlapnya dunia, dan yang terpenting adalah mempererat tali persaudaraan

\subsection{Kesederhanaan Wabicha}

Seperti sudah disebutkan dalam bagian Pendahuluan, wabi dapat diartikan sebagai kesederhanaan. Sementara, kata wabi sendiri dalam The Kodansha Bilingual Encyclopedia of Japan didefinisikan sebagai sebuah prinsip estetika dan moral yang cenderung pada ketenangan dan bebas dari permasalahan duniawi (Nomasa, 1998). Bebas dari permasalahan duniawi ini juga dapat dimaknai sebagai bebas dari kekhawatiran dan hal-hal yang bersifat materi. Prinsip yang menekankan pada kesederhanaan, keindahan, dan ketenangan ini merupakan konsep utama dalam estetika chanoyu. Dengan prinsip ini, Rikyū menegaskan bahwa sangatlah penting untuk mencari "kekayaan dalam kepapaan" dan "keindahan dalam kesederhanaan". Dengan kata lain, dalam wabi seseorang diajak untuk dapat menghargai dan menikmati apa yang ada di sekitarnya, sesederhana apa pun itu.

Selain wabi, terdapat juga istilah sabi yang umumnya digunakan mengikuti kata wabi. Sabi berasal dari kata 寂しい (sabishii) yang berarti kesendirian. Menurut
The Kodansha Bilingual Encyclopedia of Japan, istilah ini dapat diartikan secara lebih luas sebagai "pemisahan diri dari keramaian untuk mencari keindahan", suatu pandangan tipikal dari ajaran Buddha di abad pertengahan. Apabila kedua kata ini digunakan dalam satu rangkaian, maka wabi-sabi dapat diartikan sebagai "ketidaksempurnaan, ketidaktetapan, dan ketidaklengkapan". Dalam Stanford Encyclopedia of Philosophy tentang Japanese Aesthetics, ini merupakan bagian dari dua hal yang dapat dilihat dalam kebudayaan Jepang (http://plato.stanford.edu/entries/japaneseaesthetics/), yaitu:

1. Ketidaktetapan

Hal ini berdasarkan pada ajaran Buddha Zen yang perwujudannya dapat dilihat pada seni tradisional Jepang yang di dalamnya terkadang mengandung kesedihan, tetapi terkadang juga mengandung kegembiraan, seperti yang ada dalam haiku.

2. Cara

Hal ini berhubungan erat dengan Konfusianisme yang masuk ke Jepang, seperti yang terdapat dalam chanoyu (cara meminum teh), shodo (cara menulis/kaligrafi), dan lainlain.

Sementara, ciri-ciri keindahan menurut estetika wabi-sabi adalah asimetris, tidak halus, sederhana, akrab (mudah/sering dijumpai), dan alamiah. Dengan demikian, suatu benda atau karya seni yang memiliki bentuk sedikit kurang sempurna justru berharga lebih tinggi daripada yang sempurna, misalnya seperti dapat dilihat pada permukaan chawan yang kurang halus atau lingkaran chawan yang tidak seratus persen bundar (Plutschow, 1999).

Chanoyu adalah sebuah wadah dimana pemahaman akan prinsip wabi dikembangkan secara penuh. Dengan demikian, wabicha yang dipelopori oleh Sen no Rikyū dapat dianggap sebagai sebuah cara untuk lebih menghargai tata cara dan peralatan chanoyu lokal yang lebih sederhana, dibandingkan dengan tata cara dan peralatan dari Cina yang jauh lebih 
mewah dan mahal. Rikyū mendesain ulang sendiri tata cara, peralatan, dan chashitsu yang lebih sederhana tersebut. Sementara dalam pembuatannya, Rikyū seringkali bekerja sama dengan seniman lokal dengan bahan-bahan lokal pula. Berikut ini adalah perwujudan wabi dalam chanoyu secara kongkrit dan konsep beserta penjelasannya.

1. Secara kongkrit

Taman di luar chashitsu didesain sesederhana mungkin dengan pepohonan dan tanaman hijau supaya berkesan sejuk dan asri, misalnya cemara dan bambu. Bebatuan yang ada hanya yang memiliki fungsi, misalnya fumi-ishi sebagai pijakan menuju pintu masuk dan chōzubachi sebagai bejana batu tempat membasuh tangan dan mulut sebelum memasuki chashitsu. Dinding kayu dan atap jerami chashitsu terlihat sangat bersahaja, seperti rumah-rumah di pedesaan.

Chabana sebagai bunga penghias yang diletakkan di tokonoma, dirangkai secara sederhana dan bunganya umumnya didapat dari sekitar chashitsu atau tempat lain yang tidak terlalu jauh. Bunga yang digunakan sangat bergantung pada musim dan jumlah tangkainya tidak ditentukan. Kakejiku yang digantung di tokonoma pun berupa lukisan sederhana atau kaligrafi dari seniman lokal.

Peralatan minum tehnya dibuat dari bahan-bahan lokal yang sederhana, misalnya kayu dan bambu untuk sendok dan pengaduk teh, bukan perak atau logam lainnya. Chawan seringkali hanya diberi motif hiasan sederhana dengan warna yang bersahaja, bahkan kadangkadang tanpa motif sama sekali. Sementara, tamu yang diundang berasal dari kelas mana pun, baik dari kelas atas sampai kelas yang paling bawah.

2. Secara konsep

Pembacaan haiku yang diilhami dari ajaran Buddha Zen oleh sang tuan rumah bertujuan untuk menambah nilai-nilai spiritual dan secara tidak langsung mengajak seseorang untuk menjalankan hidup sederhana, menyatu dengan alam, serta sekaligus sebagai sarana pembersihan rohani.

Dengan merunduk masuk melalui nijiriguchi, seseorang diharapkan mampu untuk selalu menghormati orang lain, menjaga emosi, dan bersifat rendah hati. Chashitsu yang kecil akan menghapus batas ruang dan status sosial seseorang dengan orang lain, sehingga akan tercipta suasana akrab.

Kebersihan jasmani dan rohani para peserta chanoyu serta ruang dan peralatannya merupakan keharusan, karena kebersihan merupakan representasi dari kesucian.

Dengan jumlah peserta yang terbatas, maka akan lebih mudah untuk membuat seseorang merasa lebih tenang dan lebih menyatu dengan alam serta lingkungan sekitarnya. Dengan ketenangan pikiran, maka seseorang akan dapat merasakan jiwanya menjadi lebih bersih.

Dalam sebuah artikel tentang chanoyu yang dimuat dalam majalah khusus tentang seni dan budaya Jepang, yaitu Kateigaho, disebutkan bahwa dalam chanoyu-lah seseorang mengekspresikan penghargaannya dalam diam, karena tindakan seseorang akan mengungkapkan lebih banyak daripada kata-kata. Etiket yang benar dalam ritual ini menunjukkan penghargaan, baik oleh tuan rumah kepada sang tamu maupun sebaliknya (http://int.kateigaho.com/aut04/kyoto-teaceremony.html).

\section{SIMPULAN}

Teh dalam chanoyu bukan hanya dituang dengan air panas lalu diminum, tapi sebagai seni dalam arti luas. Teh disiapkan secara khusus oleh tuan rumah yang telah mendalami seni upacara minum teh dan dinikmati sekelompok tamu di ruangan khusus untuk minum teh yang disebut chashitsu. Tuan rumah sebagai pembawa upacara bertanggung jawab dalam mempersiapkan chashitsu yang baik untuk tamu. Hal ini dikarenakan ritual minum teh mencerminkan kepribadian dan pengetahuan tuan rumah yang mencakup antara lain tujuan hidup, cara berpikir, agama, apresiasi peralatan ritual minum teh, dan cara 
meletakkan benda-benda yang memiliki nilai seni di dalam chashitsu. Selain itu, juga mencakup berbagai pengetahuan seni secara umum yang bergantung pada aliran upacara minum teh yang dianut.

Seni upacara minum teh memerlukan pendalaman selama bertahun-tahun dengan penyempurnaan yang berlangsung seumur hidup. Tamu yang diundang secara formal untuk ritual ini juga harus mempelajari tata krama, kebiasaan, basa-basi, etika meminum teh, dan etika menikmati makanan yang dihidangkan.

Wabi-sabi sebagai sebuah prinsip estetika dan moral yang menekankan pada kesederhanaan, keindahan, dan ketenangan adalah konsep utama dalam estetika chanoyu, terutama pada wabicha. Ciri-ciri keindahan menurut estetika wabi-sabi yang asimetris, tidak halus, sederhana, akrab (mudah/sering dijumpai), dan alamiah, dapat dilihat pada perwujudan wabi dalam chanoyu. Perwujudannya secara kongkrit terletak pada penggunaan tempat, hiasan, dan peralatan yang sederhana tetapi tetap mengandung nilai keindahan untuk dinikmati. Sementara, perwujudannya secara konsep terletak pada jiwa chanoyu itu sendiri maupun para pesertanya. Sen no Rikyū dengan wabicha-nya tidak mengajak seseorang untuk menjadi penganut Buddha Zen, melainkan untuk mengambil hal-hal positif yang terdapat dalam ajaran tersebut. Dapat dikatakan bahwa mengikuti prosesi chanoyu adalah salah satu cara untuk memperoleh ketenangan.

\section{DAFTAR PUSTAKA}

Danandjaja, James. 1997. Folklor Jepang Dilihat dari Kacamata Indonesia. Jakarta : Pustaka Utama Grafiti.

Lewis, Richard D. 1999. When Cultures Collide; Managing Successfully Across Cultures. London: Nicholas Brealey Publishing Ltd.

Nomasa, Wako. 1998. The Kodansha Bilingual Encyclopedia of Japan, Tokyo : Kodansha International, Ltd.

Okakura, Kakuzo. 1989. The Book of Tea. Tokyo : Kodansha International, Ltd.

Plutschow, Herbert. 1986. Historical Chanoyu. Tokyo : The Japan Times, Ltd.

$$
\text { 1999. "An }
$$

Anthropological Perspective on the Japanese Tea Ceremony" dalam Anthropoetics 5, no. 1 (Spring/Summer 1999). East Asian Languages \& Cultures, University of California at Los Angeles.

Railey, Jennifer McMahon. 1997. "Dependent Origination and The
Dual-nature of The Japanese Aesthetic" dalam Asian Philosophy Vol.7 No.2. Hal.123-133. Department of Philosophy, State University of New York.

Sadler, A.L. 1962. Cha-no-yu. Tokyo : Charles E. Tuttle, Co.

Sumardjo, Jakob. 2000. Filsafat Seni. Bandung : Penerbit ITB.

http://int.kateigaho.com/aut04/kyoto-teaceremony.html

http://plato.stanford.edu/entries/japaneseaesthetics/

http://web-japan.org/

http://www.anthropoetics.ucla.edu/ap0501/t ea.htm

http://www.teahyakka.com/yinyanglayout.ht $\mathrm{ml}$ 